\title{
Determinants of women's likelihood of vaginal self-sampling for human papillomavirus to screen for cervical cancer in Taiwan: a cross-sectional study
}

Shu-Ling Chen ${ }^{1}$, Pao-Chun Hsieh², Chia-Hui Chou ${ }^{1}$ and Ya-Ling Tzeng ${ }^{3,4^{*}}$

\begin{abstract}
Background: Many Taiwanese women (43.8\%) did not participate in regular cervical screening in 2011. An alternative to cervical screening, self-sampling for human papillomavirus (HPV), has been available at no cost under Taiwan's National Health Insurance since 2010, but the extent and likelihood of HPV self-sampling were unknown.

Methods: A cross-sectional study was performed to explore determinants of women's likelihood of HPV self-sampling. Data were collected by questionnaire from a convenience sample of 500 women attending hospital gynecologic clinics in central Taiwan from June to October 2012. Data were analyzed by descriptive statistics, chi-square test, and logistic regression.

Results: Of 500 respondents, 297 (59.4\%) had heard of HPV; of these 297 women, 69 (23\%) had self-sampled for HPV. Among the 297women who had heard of HPV, 234 (78.8\%) considered cost a priority for HPV self-sampling. Likelihood of HPV self-sampling was determined by previous Pap testing, high perceived risk of cervical cancer, willingness to self-sample for HPV, high HPV knowledge, and cost as a priority consideration.

Conclusions: Outreach efforts to increase the acceptability of self-sampling for HPV testing rates should target women who have had a Pap test, perceive themselves at high risk for cervical cancer, are willing to self-sample for HPV, have a high level of HPV knowledge, and for whom the cost of self-sampling covered by health insurance is a priority.
\end{abstract}

Keywords: Cervical cancer, Pap smear, Human Papillomavirus, Self-sampling

\section{Background}

Cervical cancer is the second most common cancer in women worldwide, with over 529,000 new cases and 275,000 deaths in 2010 [1]. Most women with cervical cancer have never been or are not regularly screened [2]. However, cervical screening is crucial for early detection of precancerous lesions. Cervical cancer screening has traditionally been done by physicians using the Pap test, which many women perceive as uncomfortable and embarrassing [3-7]. A potential alternative to the Pap test in Western countries has been vaginal self-sampling for human papillomavirus (HPV) [5,8,9], the causative

\footnotetext{
*Correspondence: tyaling@mail.cmu.edu.tw

${ }^{3}$ School of Nursing, China Medical University, Taichung, Taiwan

${ }^{4}$ Department of Nursing, China Medical University Hospital, Taichung, Taiwan Full list of author information is available at the end of the article
}

agent for most cervical cancers [10]. HPV self-sampling is easy to perform, less painful, less embarrassing, and less anxiety provoking than the Pap test $[11,12]$. Furthermore, HPV self-sampling has been reported to increase cervical cancer screening compliance for women who have never or not regularly been screened for cervical cancer [5,13].

Cervical cancer was the seventh leading cause of cancer mortality among Taiwanese women in 2012 [14]. Taiwan's National Health Insurance has been reimbursing women $\geq 30$ years old for annual Pap tests since 1995 and women $\geq 36$ years old who had not had a Pap test within $\geq 6$ years for self-collected HPV samples since 2010 [14]. This reimbursement policy led to a gradual but significant increase in annual participation in Pap screening from $35.0 \%$ in 1997 to $56.2 \%$ in 2011 [14]. 
Despite this increase, $43.8 \%$ of Taiwanese women still have never or not regularly participated in cervical screening in 2011 [14]. Self-collected HPV sampling may improve the cervical cancer screening rate for women who currently do not participate in regular cervical cancer screening in Taiwan, as in western countries $[3,13]$. However, little research has been done on HPV selfsampling in Taiwan. It is important to identify and target women who are likely to accept self-collected HPV sampling for cervical screening. Thus, the aim of this study was to explore determinants of women's likelihood of self-sampling for HPV testing.

To explore the likelihood of self-sampling for HPV, we reviewed the literature on factors impacting uptake of HPV vaccination, Pap test, and cervical cancer screening because these factors may also affect uptake of HPV selfsampling. For example, women's willingness to collect their own HPV samples is crucial [15] because it has been shown to affect their readiness to self-sample for HPV. In addition, two prerequisites for making an informed decision about HPV vaccination are awareness of HPV (having heard of HPV) and knowledge of HPV [16]. The uptake of cervical screening services was influenced by knowledge of cervical cancer $[17,18]$, previous Pap testing [11], educational level [3,11], and household income 1 [19], but was not associated with marital status [20]. Furthermore, barriers to Pap testing such as the issues of time [20,21], cost [5,18], and clinical site [21] might be barriers to women's likelihood of self-sampling for HPV.

\section{Methods}

\section{Sample and setting}

This cross-sectional study was conducted between June and October, 2012. A convenience sample was recruited from women seeking obstetrical and gynecological health care but not cervical screening at the gynecologic clinics of a regional hospital in central Taiwan. Women were excluded if they reported a history of cervical cancer because these women received different cervical screening recommendations [22]. After the study was approved by the Cheng Ching Hospital's Institutional Review Board (approval \# HP120013), a clinical nurse approached women in the clinic and told them about the study and their rights. Those who agreed to participate signed informed consent and were given a small gift (NT\$ 100 [approximately US\$3] cash coupon).

\section{Data collection}

Data were collected by questionnaire from June to October 2012. Women respondents were first asked if they had heard of HPV. If a woman responded "yes", she was asked three HPV-related questions: her perceived risk of cervical cancer (high/low), her priority considerations for HPV self-sampling (clinical site, time, and cost), and if she had ever self-sampled for HPV (yes/no). If a woman had not heard of HPV, she skipped the first three questions (see "Determinants of the likelihood of self-sampling for HPV" below). All women, regardless of having heard of HPV, were then asked about their willingness to self-sample for HPV (willing, unwilling, undecided) and extent of HPV knowledge. HPV knowledge was measured by 21 true/false items drawn from previous research [23]. Percentages of correct answers for women who had heard of HPV are shown in (Additional file 1). Extent of HPV knowledge was categorized as high, moderate, and low based on the number of correct answers above the mode score, between the median and mode scores, or below the median score, respectively. Scores of $\geq 15$ points were coded as a high level of knowledge, those with 13 to 14 points were coded as moderate knowledge, and those with $\leq 12$ points were coded as low knowledge.

Demographic variables included age range $(18-29,30-$ $39,40-49,50-65$ years), education ( $\leq$ high school, college degree, bachelor's degree, $\geq$ graduate degree), annual household income $(\leq 500,000 ; 510,000-1,000,000 ; 1,010,000-1,50$ $0,000 ; 1,510,000-2,000,000 ; \geq 2,010,000 \mathrm{NT} \$)$, marital status (single [divorced, separated, widowed] vs. married), and residential area (city, town, rural). A related clinical variable was previous Pap testing (yes/no).

\section{Data analysis}

All the data were entered and analyzed using SPSS version 14.0 for Windows (SPSS Inc., Chicago, IL). Data were analyzed by descriptive statistics, the chi-square test, and multivariate logistic regression. All women were asked about their willingness to self-sample for HPV and extent of HPV knowledge because we wanted to determine whether having heard of HPV was associated with willingness to self-sample and HPV knowledge.

\section{Results}

\section{Sample characteristics}

The 500 women who completed our questionnaire were 18-65 years old, with the largest proportion 30-39 years old $(n=216,43.2 \%)$. A majority of the women was married $(n=372,74.4 \%)$, had at least a college education $(n=331,66.2 \%)$, had an annual household income of $<$ NT\$1,000,000 $(n=397,79.4 \%)$, and lived in a city $(n=378,75.6 \%)$. The majority of women had had Pap testing $(n=331,66.2 \%)$ and had heard of HPV $(n=297,59.4 \%)$. For details, see Table 1.

Among the 297 women who had heard of HPV, a majority had had Pap testing $(n=206,69.4 \%)$ and perceived that they had a low risk of cervical cancer $(n=207,69.7 \%)$. Regarding priority considerations for HPV self-sampling, a majority $(n=234,78.8 \%)$ was concerned about cost. Two- 
Table 1 Sample characteristics

\begin{tabular}{|c|c|c|c|c|c|}
\hline Characteristics & $n$ & $\%$ & & $n$ & $\%$ \\
\hline All women $(N=500)$ & & & \multicolumn{3}{|c|}{ Women who heard of HPV $(N=297)$} \\
\hline Age, years & & & Previous Pap testing & & \\
\hline$\leq 29$ & 138 & 27.6 & Yes & 206 & 69.4 \\
\hline $30-39$ & 216 & 43.2 & No & 91 & 30.6 \\
\hline $40-49$ & 106 & 21.2 & \multicolumn{3}{|c|}{ Perceived risk of cervical cancer } \\
\hline$\geq 50$ & 40 & 8.0 & High & 90 & 30.3 \\
\hline Education & & & Low & 207 & 69.7 \\
\hline$\leq$ High school & 169 & 33.8 & \multicolumn{3}{|c|}{ Willingness to self-sample for HPV } \\
\hline College & 131 & 26.2 & Willing & 196 & 66.0 \\
\hline Baccalaureate degree & 177 & 35.4 & Unwilling/undecided & 101 & 34.0 \\
\hline$\geq$ Graduate degree & 23 & 4.6 & \multicolumn{3}{|l|}{ HPV knowledge ${ }^{b}$} \\
\hline Annual household income (NT\$) & & & High & 76 & 25.6 \\
\hline$\leq 500,000$ & 194 & 38.8 & Moderate & 127 & 42.8 \\
\hline $510,000-1,000,000$ & 203 & 40.6 & Low & 94 & 31.6 \\
\hline $1,010,000-1,500,000$ & 67 & 13.4 & \multicolumn{3}{|c|}{ Priority consideration for HPV self-sampling } \\
\hline $1,510,000-2,000,000$ & 22 & 4.4 & Cost & 234 & 78.8 \\
\hline$\geq 2,010,000$ & 14 & 2.8 & Clinical site/time & 63 & 21.2 \\
\hline \multicolumn{6}{|l|}{ Marital status } \\
\hline Single $(D, S, W)^{a}$ & 128 & 25.6 & & & \\
\hline Married & 372 & 74.4 & & & \\
\hline \multicolumn{6}{|l|}{ Residential area } \\
\hline City & 378 & 75.6 & & & \\
\hline Town & 79 & 15.8 & & & \\
\hline Rural & 43 & 8.6 & & & \\
\hline \multicolumn{6}{|l|}{ Previous Pap testing } \\
\hline Yes & 331 & 66.2 & & & \\
\hline No & 169 & 33.6 & & & \\
\hline \multicolumn{6}{|l|}{ Heard of HPV } \\
\hline Yes & 297 & 59.4 & & & \\
\hline No & 203 & 40.6 & & & \\
\hline
\end{tabular}

${ }^{\mathrm{a}} \mathrm{D}$ refers to divorced, $\mathrm{S}$ refers to separated, $\mathrm{W}$ refers to widowed.

b HPV knowledge was categorized as high, moderate, and low based on the number of correct answers above the mode score, between median and mode score, or below the median score, respectively. Scores of $\geq 15$ points were coded as "high" knowledge, those with 13 to 14 points were coded as "moderate" knowledge, and those with $\leq 12$ points were coded as low knowledge.

thirds of these women were willing to self-sample for HPV ( $n=196,66 \%)$, and the largest proportion had a moderate level of HPV knowledge ( $n=127,42.8 \%)$. For details, see Table 1 . Most of these women also understood that HPV can cause cervical cancer (97.3\%), can cause serious health problems for women (94.9\%), cannot be transmitted by kissing (94.3\%), and can be sexually transmitted (92.9\%). However, few of them knew that using condoms during sexual intercourse is only partially effective in preventing the spread of HPV (8.4\%), HPV infection cannot be treated (13.8\%), and HPV cannot be transmitted by the exchange of bodily fluids (blood, semen) (14.1\%) (Additional file 1).

\section{Determinants of the likelihood of self-sampling for HPV}

If a woman had not heard of HPV, her data were not included in the analysis of determinants of women's likelihood to self-sample for HPV because not having heard of HPV indicates unawareness of HPV [24]. Associations between demographic/clinical variables and the likelihood of HPV self-sampling among those who had heard of HPV were analyzed using $X^{2}$ statistics. Significant associations $(p<0.05)$ were used as the cutoff for selecting determinants in multivariate logistic regression analysis for the likelihood of women's self-sampling for HPV.

Among the 297 women who had heard of HPV, 69 (23\%) had self-sampled for HPV (Table 2). Our analysis 
Table 2 Characteristics associated with the likelihood of HPV self-sampling among women who had heard of HPV

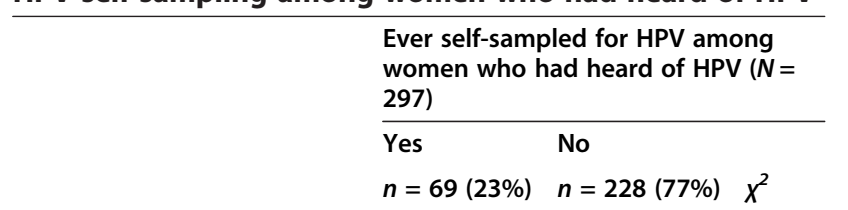

\begin{tabular}{lll} 
Characteristic & $\boldsymbol{n}(\%)$ & $\boldsymbol{n}(\%)$ \\
\hline $\begin{array}{lll}\text { Age range, years } \\
\leq 29\end{array}$ & $9(13.0)$ & $60(87.0)$ \\
$30-39$ & $33(25.2)$ & $98(74.8)$ \\
$40-49$ & $19(24.7)$ & $58(75.3)$ \\
$\geq 50$ & $8(40.0)$ & $12(60.0)$
\end{tabular}

Education

$\begin{array}{lll}\leq \text { High school } & 18(23.4) & 59(76.6) \\ \text { College } & 18(21.7) & 65(78.3) \\ \text { Bachelor's degree } & 27(22.5) & 93(77.5) \\ \geq \text { Graduate degree } & 6(35.3) & 11(64.7)\end{array}$

Annual household income (NT\$)

$\leq 500,000$

$16(16.8)$

79 (83.2)

510,000-1,000,000

$32(24.6)$

$98(75.4)$

$1,010,000-1,500,000$

$10(24.4)$

$31(75.6)$

$1,510,000-2,000,000$

$5(26.3)$

$14(73.6)$

$\geq 2,010,000$

$6(50.0)$

$6(50.0)$

Marital status

Single $(D, S, W)^{a}$

17 (21.5)

$62(78.5)$

Married

$52(23.9)$

$166(76.1)$

Residential area

City

55 (23.6)

$178(76.4)$

Town

$10(22.7)$

$34(77.3)$

Rural

$4(20.0)$

$16(80.0)$

Previous Pap testing

Yes

67 (32.5)

$139(67.5)$

No

$2(2.2)$

$89(97.8)$

Perceived risk of cervical cancer

High

$29(32.2)$

$61(67.8)$

Low

40 (19.3)

$167(80.7)$

Willingness to self-sample

Willing

54 (27.6)

$142(72.4)$

Unwilling/undecided

15 (14.9)

$86(85.1)$

HPV knowledge ${ }^{b}$

High

Moderate

$28(36.8)$

$48(63.2)$

Low

$26(20.5)$

$101(79.5)$

$15(16.0)$

Table 2 Characteristics associated with the likelihood of HPV self-sampling among women who had heard of HPV (Continued)

Priority consideration for

HPV self-sampling

\begin{tabular}{llll} 
Cost & $47(20.1)$ & $187(79.9)$ & $6.125^{*}$ \\
Clinical site/time & $22(34.9)$ & $41(65.1)$ \\
\hline
\end{tabular}

${ }^{a} D$ refers to divorced, $S$ refers to separated, $W$ refers to widowed.

${ }^{b}$ HPV knowledge was categorized as high, moderate, and low based on the number of correct answers above the mode score, between median and mode score, or below the median score, respectively. Scores of $\geq 15$ points were coded as a high level of knowledge, those with 13 to 14 points were coded as moderate knowledge, and those with $\leq 12$ points were coded as low knowledge.

${ }^{*} \mathrm{p}<0.05,{ }^{* *} \mathrm{p}<0.01,{ }^{* * *} \mathrm{p}<0.001$.

1.54

showed that, among women who had heard of HPV, ever self-sampling for HPV was significantly associated with five factors: previous Pap testing, perceived risk of cervical cancer, willingness to self-sample, extent of HPV knowledge, and priority considerations for HPV selfsampling. Women who had previous Pap testing and high perceived risk of cervical cancer were more likely to self-sample for HPV than women with no previous Pap testing and low perceived risk of cervical cancer, respectively. Women who were willing to self-sample for HPV were more likely to self-sample for HPV than those who were unwilling and undecided. Women with high HPV knowledge were more likely to self-sample for HPV than those with low and moderate HPV knowledge. Women with a priority consideration of cost were less likely to self-sample for HPV than those with a priority consideration of clinical site/time. In addition, bivariate analyses revealed that, among women who had heard of HPV, ever self-sampling for HPV was not significantly associated with demographic characteristics. For details, see Table 2.

The results of multivariate logistic regression analyses are presented as factors predicting the likelihood of selfsampling for HPV (Table 3). The results show that the full model, which considered all five independent variables together, was statistically significant $\left(\chi^{2}=72.933, \mathrm{df}=6\right.$, $n=297, \mathrm{p}<0.001)$. This result implies that the odds of a woman self-sampling for HPV were related to these five independent variables, i.e., previous Pap testing, perceived risk of cervical cancer, willingness to self-sample, extent of HPV knowledge, and priority considerations for HPV selfsampling. This model also passed tests of goodness of fit and of collinearity. Regarding goodness of fit, the final model passed the Hosmer and Lemeshow test and was not significant $(\mathrm{p}=0.945)$. Each variable also passed tests for collinearity, with all tolerance scores $>0.95$, which exceeded the suggested criterion of 0.1 [25], and all VIF (variance inflation factor) scores $<2$, which is well below the cutoff value of 10 [26]. This model correctly classified $78.8 \%$ of women who had self-sampled for HPV. The 


\begin{tabular}{|c|c|c|}
\hline Determinant & $\beta$ & $\begin{array}{l}\text { Odds ratio } \\
\text { (95\% confidence interval) }\end{array}$ \\
\hline \multicolumn{3}{|l|}{ Previous Pap testing } \\
\hline Yes & $3.09^{* * *}$ & $22.00(5.10,95.02)$ \\
\hline No & $1(\text { ref })^{a}$ & \\
\hline \multicolumn{3}{|l|}{ Perceived risk of cervical cancer } \\
\hline High & $0.81^{*}$ & $2.25(1.17,4.32)$ \\
\hline Low & $1(\text { ref })^{a}$ & \\
\hline \multicolumn{3}{|l|}{ Willingness to self-sample } \\
\hline Willing & $1.13^{* *}$ & $3.09(1.41,6.76)$ \\
\hline Unwilling/undecided & $1(\text { ref })^{a}$ & \\
\hline \multicolumn{3}{|l|}{ HPV knowledge } \\
\hline $\begin{array}{l}\text { High } \\
\text { ( } \geq 70 \% \text { correct answers) }\end{array}$ & $1.24^{* *}$ & $3.47(1.53,7.88)$ \\
\hline $\begin{array}{l}\text { Moderate } \\
\text { (60\%-69\% correct answers) }\end{array}$ & 0.22 & $1.24(0.58,2.67)$ \\
\hline $\begin{array}{l}\text { Low } \\
\text { ( } \leq 59 \% \text { correct answers) }\end{array}$ & $1(\mathrm{ref})^{\mathrm{a}}$ & \\
\hline \multicolumn{3}{|l|}{$\begin{array}{l}\text { Priority consideration for } \\
\text { HPV self-sampling }\end{array}$} \\
\hline Cost & $-1.30^{* *}$ & $0.27(0.13,0.59)$ \\
\hline Clinical site/time & $1(\text { ref })^{a}$ & \\
\hline Constant & $-4.39^{* * *}$ & 0.001 \\
\hline
\end{tabular}

${ }^{a}$ ref indicates reference group.

$x^{2}: 72.933, \mathrm{df}=6$, Hosmer \& Lemeshow: $p=0.945,-2 \log$ likelihood: 249.056, Cox \& Snell $R^{2}: 0.218$, Nagelkerke $R^{2}: 0.329$.

${ }^{*} p<0.05,{ }^{* *} p<0.01,{ }^{* * *} p<0.001$.

"pseudo" R estimates indicate that the model explained between 21.8\% (Cox and Snell $R^{2}$ ) and 32.9\% (Nagelkerke $R^{2}$ ) of variance in the likelihood of self-sampling for HPV.

The odds ratios in Table 3 indicate the factor increases (ratios $>1$ ) and decreases (ratios $<1$ ) in a woman's odds of self-sampling for HPV if all other variables are held constant. The strongest determinant of the likelihood of self-sampling for HPV was having had a previous Pap test. Women who had a previous Pap test had 22 times the odds of self-sampling for HPV than those who had not (OR 22.00, 95\% CI 5.10-95.02, $\mathrm{p}<0.001$ ).

Another strong determinant of women's likelihood of self-sampling for HPV was priority considerations for HPV self-sampling (Table 3). Women whose priority consideration was cost had significantly lower odds of self-sampling for HPV than those whose priority was clinical site/time considerations (OR 0.27, 95\% CI 0.13$0.59, \mathrm{p}<0.01$ ).

Other determinants that significantly contributed to the model were extent of HPV knowledge, willingness to selfsample, and perceived risk of cervical cancer (Table 3). Women with high HPV knowledge had significantly greater odds of self-sampling for HPV than those with low
HPV knowledge (OR 3.47, 95\% CI 1.53-7.88, $\mathrm{p}<0.01$ ). Women who were willing to self-sample for HPV had significantly greater odds of self-sampling for HPV than women who were unwilling/undecided (OR 3.09, 95\% CI 1.41-6.76, $\mathrm{p}<0.01$ ). Women whose perceived risk of cervical cancer was high had significantly greater odds of self-sampling for HPV than women who perceived a low risk (OR 2.25, 95\% CI 1.17-4.32, $\mathrm{p}<0.05)$.

\section{Discussion}

This study contributes to knowledge about the factors related to the likelihood of a clinical sample of Taiwanese women to self-sample for HPV. The majority of our women respondents (59.4\%) had heard of HPV, and most of these women (97.3\%) understood that HPV causes cervical cancer. However, the remaining $40.6 \%$ of our sample had not heard of HPV and did not understand its link to cervical cancer. Although a majority of women had heard of HPV and had moderate-to-high levels of HPV knowledge, they misunderstood important information about the virus, such as condom use only partially protects against transmission of HPV and HPV cannot be transmitted by exchange of bodily fluids (blood, semen). Our results echo those of a study with US college students, most of whom had heard of HPV and had moderate HPV knowledge but did not understand important HPV facts related to cervical cancer [24]. In addition, women who had heard of HPV were more likely to be willing to self-sample for HPV than those who had not heard of HPV. Together, these findings highlight the importance of disseminating information about HPV.

Women's likelihood of self-sampling for HPV was most strongly predicted by previous Pap testing, consistent with the strongest determinant of intent to undergo future Pap smear screening being prior screening [18]. This result is not surprising, given that most women know and accept the Pap smear as an effective method for cervical screening despite the side effects of discomfort and embarrassment $[3,6,27]$. In this respect, selfsampling for HPV is a less painful and embarrassing procedure than the Pap test. Thus, women who have undergone previous Pap testing are strongly enough motivated to participate regularly in self-sampling for HPV to prevent cervical cancer or detect it early. We note the discrepancy in our findings between the number of women who had had a Pap test $(n=331)$ and those who had heard of HPV $(n=297)$, suggesting that some women who had a Pap test had not heard of HPV. This may have been due to their doctors not explaining that HPV has been linked to the cytological changes that the Pap test detects or the women not understanding or remembering their doctor's explanation. 
Another strong determinant of women's likelihood of self-sampling for HPV was cost priority consideration. Cost is a highly negative predictor of self-sampling for $\mathrm{HPV}$. This finding is similar to other studies that vaccine's cost would impede vaccination $[16,28,29]$.

Three other determinants of women's likelihood of self-sampling for HPV were extent of HPV knowledge, willingness to self-sample for HPV and perceived risk of cervical cancer. Similar to a previous report that Turkish women's acceptance of Kato's device as an alternative to the Pap smear was related to knowledge of HPV and cancer [6]. This result, taken with our finding that even women with moderate-to-high HPV knowledge did not understand some important aspects of HPV knowledge suggest the importance of education programs to increase the likelihood of self-sampling for HPV.

Our findings are consistent with previous findings that willingness to self-sample for HPV was a determinant of future HPV self-sampling [9]. Willingness to self-sample for HPV is a logical predictor for likelihood of HPV selfsampling because without willingness, a health behavior will not occur [30]. Additionally, our clinical sample's likelihood of HPV self-sampling was predicted by a higher perceived likelihood of getting cervical cancer. This result is consistent with research on acceptability of Kato's device for cervical cancer screening [6] and low perceived risk of cervical cancer as a major reason for Malaysian women never having a Pap smear [31].

\section{Limitations}

The results of our study are subject to some limitations. First, our results are based on data from a gynecological clinic sample recruited from central Taiwan, and only 69 respondents had ever self-sampled for HPV. Thus, the results may not be generalizable to all women in Taiwan. Second, not having heard of HPV does not mean that a woman has no opinion of her risk of cervical cancer or did not self-sample for HPV. Further research should ask women about their perceived risk of cervical cancer and whether they have ever self-sampled for HPV, regardless of whether they have heard of HPV. Third, determinants of the likelihood of HPV self-sampling were examined only among women who had heard of HPV. More research is needed to find effective methods to disseminate information about HPV to increase the proportion of women aware of HPV and to improve their understanding of the link between HPV and cervical cancer. More accurate and complete knowledge about HPV may increase cervical screening rates among women who do not regularly participate in screening by increasing their willingness to self-sample for HPV as reported for native women in Canada [13].

\section{Conclusions}

Taiwanese women's likelihood of HPV self-sampling was predicted by having had a previous Pap test, perceiving a high risk of cervical cancer, willingness to self-sample for HPV, a high level of HPV knowledge, and a cost priority consideration. Therefore, outreach efforts to increase the acceptability of self-sampling for HPV should disseminate information about HPV to increase the rate of women who have heard of HPV and target women who not only have had a Pap test, but also perceive themselves at high risk for cervical cancer, are willing to self-sample for HPV, and have a high level of HPV knowledge. Another important concern for HPV selfsampling is that its cost is covered by health insurance. These findings can be used by policy makers to plan appropriate activities and strategies to educate women about HPV self-sampling for cervical screening, as well as to target women who are likely to accept HPV selfsampling, and in turn to increase regular cervical screening participation in Taiwan.

\section{Additional file}

Additional file 1: The proportions of correct answers about HPV by women who had heard of HPV. Correct answers from [23]: Sandfort JR, Pleasant A: Knowledge, attitudes, and informational behaviors of college students in regard to the human papillomavirus. J Am Coll Health 2009, 58(2): 141-149.

Competing interests

The authors declare that they have no competing interests.

Authors' contributions

SLC, YLT: Design of the study; PCH, CHC: Data collection, data management; SLC, YLT: Data analysis, writing paper. All authors read and approved the final manuscript.

\section{Acknowledgements}

This study was supported by grant HK-CCGH-101-03 from Hung Kuang University and Cheng Ching Hospital, Taichung, Taiwan. We also sincerely thank all of the women who participated in this research.

\section{Author details}

${ }^{1}$ Department of Nursing, Hungkuang University, Taichung, Taiwan.

2Department of Obstetrics and Gynecology, Cheng Ching Hospital, Taichung, Taiwan. ${ }^{3}$ School of Nursing, China Medical University, Taichung, Taiwan.

${ }^{4}$ Department of Nursing, China Medical University Hospital, Taichung, Taiwan.

Received: 2 June 2014 Accepted: 23 October 2014

Published online: 25 November 2014

\section{References}

1. World Health Organization: WHO/ICO Information Centre. Human Papillomavirus and Related Cancers. WHO Press; 2013. http://www.hpvcentre. net/statistics/reports/XWX.pdf.

2. Spence AR, Goggin P, Franco EL: Process of care failures in invasive cervical cancer: systematic review and meta-analysis. Prev Med 2007, 45:93-106.

3. Anhang R, Nelson JA, Telerant R, Chiasson MA, Wright TC Jr: Acceptability of self-collection of specimens for HPV DNA testing in an urban population. J Womens Health 2005, 14(8):721-728. 
4. Chen SL, Chao Yu YM, Tsai DF, Chen MJ: Gynecologists' perceptions of the patient-physician relationship in pelvic examinations in Taiwan. J Psychosom Obstet Gynaecol 2008, 29(4):290-295.

5. Huynh J, Howard M, Lytwyn A: Self-collection for vaginal human papillomavirus testing: systematic review of studies asking women their perceptions. J Low Genit Tract Dis 2010, 14(4):356-362.

6. Sahin MK, Sahin G, Dikici MF, Igde FA, Yaris F: Women's perceptions and attitudes about cervical cancer in Turkey: Kato's device as an alternative to the Pap smear. Asian Pac J Cancer Prev 2014, 15(2):905-910.

7. Szarewski A, Cadman L, Ashdown-Barr L, Waller J: Exploring the acceptability of two self-sampling devices for human papillomavirus testing in the cervical screening context: a qualitative study of Muslim women in London. J Med Screen 2009, 16(4):193-198.

8. Petignat P, Faltin DL, Bruchim I, Tramèr MR, Franco EL, Coutlée F: Are self-collected samples comparable to physician-collected cervical specimens for human papillomavirus DNA testing? A systematic review and meta-analysis. Gynecol Oncol 2007, 105(2):530-535.

9. Scarinci IC, Litton AG, Garcés-Palacio IC, Partridge EE, Castle PE: Acceptability and usability of self-collected sampling for HPV testing among African-American women living in the Mississippi Delta. Womens Health Issues 2013, 23(2):e123-e130.

10. National Cancer Institute: HPV and Cancer. 2012. http://www.cancer.gov/ cancertopics/factsheet/Risk/HPV.

11. Berner A, Hassel SB, Tebeu PM, Untiet S, Kengne-Fosso G, Navarria I, Boulvain M, Vassilakos P, Petignat P: Human papillomavirus self-sampling in Cameroon: women's uncertainties over the reliability of the method are barriers to acceptance. J Low Genit Tract Dis 2013, 17(3):235-241.

12. Karwalajtys T, Howard M, Sellors JW, Kaczorowski J: Vaginal self sampling versus physician cervical sampling for HPV among younger and older women. Sex Transm Infect 2006, 82(4):337-379.

13. Zehbe I, Moeller H, Severini A, Weaver B, Escott N, Bell C, Crawford S, Bannon D, Paavola N: Feasibility of self-sampling and human papillomavirus testing for cervical cancer screening in First Nation women from Northwest Ontario, Canada: a pilot study. BMJ Open 2011, 1(1):e000030.

14. Health Promotion Administration: Ministry of Health and Welfare 2013. Cervical Cancer Screening Registry System Annual Report, Republic of China. Taipei: Department of Health, Executive Yuan; 2013. http://www.hpa.gov.tw/ BHPNet/Web/Stat/StatisticsShow.aspx?No=201304150001.

15. Petignat $P$, Vassilakos $P$ : Is it time to introduce HPV self-sampling for primary cervical cancer screening? J Natl Cancer Inst 2012, 104(3):166-167.

16. Brewer NT, Fazekas Kl: Predictors of HPV vaccine acceptability: a theory-informed, systematic review. Prev Med 2007, 45(2-3):107-114.

17. Rama CH, Villa LL, Pagliusi S, Andreoli MA, Costa MC, Aoki AL, LongattoFilho A, Eluf-Neto J: Awareness and knowledge of HPV, cervical cancer, and vaccines in young women after first delivery in São Paulo, Brazil-a cross-sectional study. BMC Women's Health 2010, 10:35-41.

18. Rositch AF, Gatuguta A, Choi RY, Guthrie BL, Mackelprang RD, Bosire R, Manyara L, Kiarie JN, Smith JS, Farquhar C: Knowledge and acceptability of Pap smears, self-sampling and HPV vaccination among adult women in Kenya. PLoS One 2012, 7(7):e40766.

19. Dzuba IG, Díaz EY, Allen B, Leonard YF, Lazcano Ponce EC, Shah KV, Bishai D, Lorincz A, Ferris D, Turnbull B, Hernández Avila M, Salmerón J: The acceptability of self-collected samples for HPV testing vs. the Pap test as alternatives in cervical cancer screening. J Womens Health Gend Based Med 2002, 11(3):265-275

20. Khanna N, Mishra SI, Tian G, Tan MT, Arnold S, Lee C, Ramachandran S, Bell $L$, Baquet $C R$, Lorincz A: Human papillomavirus detection in self-collected vaginal specimens and matched clinician-collected cervical specimens. Int J Gynecol Cancer 2007, 17(3):615-622.

21. De Alba I, Anton-Culver H, Hubbell FA, Ziogas A, Hess JR, Bracho A, Arias C Manetta A: Self-sampling for human papillomavirus in a community setting: feasibility in Hispanic women. Cancer Epidemiol Biomarkers Prev 2008, 17(8):2163-2168.

22. U.S. Preventive Services Task Force: Screening for Cervical Cancer: Recommendations and Rationale. AHRQ pub; 2014. No. 03-515A. http://www. uspreventiveservicestaskforce.org/3rduspstf/cervcan/cervcanrr.pdf.

23. Sandfort JR, Pleasant A: Knowledge, attitudes, and informational behaviors of college students in regard to the human papillomavirus. J Am Coll Health 2009, 58(2):141-149.
24. Tiro JA, Meissner HI, Kobrin S, Chollette V: What do women in the U.S. know about human papillomavirus and cervical cancer? Cancer Epidemiol Biomarkers Prev 2007, 16(2):288-294.

25. Pallant J: SPSS Survival Manual. England: Berkshire: Open University Press; 2007

26. Field A: Discovering Statistics Using SPSS. London: Sage; 2009.

27. Kahn JA, Bernstein DI, Rosenthal SL, Huang B, Kollar LM, Colyer JL, Tissot AM, Hillard PA, Witte D, Groen P, Slap GB: Acceptability of human papillomavirus self-testing in female adolescents. Sex Transm Infect 2005, 81(5):408-414

28. Barnack $\lrcorner$, Reddy DM, Swain C: Predictors of parents' willingness to vaccinate for human papillomavirus and physicians' intentions to recommend the vaccine. Womens Health Issues 2010, 20(1):28-34

29. Coleman MA, Levison J, Sangi-Haghpeykar H: HPV vaccine acceptability in Ghana, West Africa. Vaccine 2011, 29(23):3945-3950.

30. Barata PC, Mai V, Howlett R, Gagliardi AR, Stewart DE: Discussions about self-obtained samples for HPV testing as an alternative for cervical cancer prevention. J Psychosom Obstet Gynaecol 2008, 29(4):251-257.

31. Wong LP, Wong YL, Low WY, Khoo EM, Shuib R: Cervical cancer screening attitudes and beliefs of Malaysian women who have never had a Pap smear: a qualitative study. Int J Behav Med 2008, 15(4):289-292.

\section{doi:10.1186/s12905-014-0139-0}

Cite this article as: Chen et al:: Determinants of women's likelihood of vaginal self-sampling for human papillomavirus to screen for cervical cancer in Taiwan: a cross-sectional study. BMC Women's Health 2014 14:139.

\section{Submit your next manuscript to BioMed Central and take full advantage of:}

- Convenient online submission

- Thorough peer review

- No space constraints or color figure charges

- Immediate publication on acceptance

- Inclusion in PubMed, CAS, Scopus and Google Scholar

- Research which is freely available for redistribution 